\title{
PHYSICAL FITNESS, SELF-PERCEPTION AND PHYSICAL ACTIVITY IN CHILDREN WITH DIFFERENT MOTOR COMPETENCE
}

\author{
Vigdis Vedul-Kjelsås \\ Faculty of Teacher and Interpreter Education, Physical Education, Sør-Trøndelag University College, \\ Trondheim, Norway \\ Ann-Katrin Stensdotter \\ Faculty of Health Education and Social Work, Physiotherapy, Sør-Trøndelag University College, \\ Trondheim, Norway \\ Monika Haga \\ Faculty of Health Education and Social Work, Physiotherapy, Sør-Trøndelag University College, \\ Trondheim, Norway \\ Hermundur Sigmundsson \\ Department of Psychology, Norwegian University of Science and Technology (NTNU)
}

\begin{abstract}
*Corresponding author: Vigdis Vedul-Kjelsås, Faculty of Teacher Education, Physical Education, Sør-Trøndelag University college, Rotvoll Allé, 7004 Trondheim, Norway. E-mail: vigdis.vedul-kjelsas@ hist.no
\end{abstract}

\begin{abstract}
The aim of the study was to investigate if children at the age of 11 with total scores at or above 13.5 (lower motor competence) on Motor assessment Battery for Children (MABC) differ from children scoring below 13.5 (higher motor competence) in physical fitness, self-perception and physical activity. A total of 67 children completed the Test of Physical Fitness and Harter's Self-perception Profile for Children, and two questions concerning physical activity. Children with lower motor competence performed poorer on all fitness tasks, were less physically active and had lower perception of athletic competence and social acceptance, than the group with higher motor competence. These findings indicate that lower levels of motor competence may impact several health related variables in children. In this respect the importance of experience with the tasks measured are discussed. Additionally, the benefits of a mastery-oriented climate to promote physical activity in school, especially for children with lower motor competence, are emphasized.
\end{abstract}

Keywords: motor skills, motor difficulties, health, school, physical education

\section{INTRODUCTION}

Skilled movement is described as a fundamental component of human life, and a person's level of performance in different motor acts, including coordination of both fine and gross motor skills is defined as motor competence (Henderson \& Sugden, 1992). Level of motor competence is found to be related to physical fitness (Haga, 2008a; Hands, 2008) and self-perception (Barnett, Morgan, van Beurden, \& Beard, 2008; VedulKjelsås, Sigmundsson, Stensdotter, \& Haga, 2012). Additionally, motor competence might be seen as a determinant of participation in and level of physical activity (Wrotniak, Epstein, Dorn, Jones, \& Kondilis, 2006).
Especially, it is emphasized that children with low motor competence are less physically active than children with higher motor competence (Barnett et al., 2008; Barnett, van Beurden, Morgan, Brooks, \& Beard, 2009; Cantell, Crawford, \& Tish Doyle-Baker, 2008; Williams et al., 2008; Wrotniak et al., 2006).

Physical activity is defined as the movement of the body produced by the skeletal muscles, resulting in energy expenditure above resting values (Bouchard, Blair, \& Haskell, 2007; Caspersen, Powell, \& Christenson, 1985). Evidence of positive health effects from participation in physical activity is considerable, for example maintenance of a healthy weight, increased bone mass, prevention of cardiovascular risk factors and 
improved psychosocial outcomes (Andersen et al., 2006; Boreham \& Riddoch, 2001; Cairney, Hay, Faught, \& Hawes, 2005; Sallis, Prochaska, \& Taylor, 2000). Reduced level of physical activity in children with low motor competence may be associated with lower performance level on several components of physical fitness, such as cardiovascular endurance, muscular strength and muscular endurance and speed, compared to their typically developing peers (Haga, 2008b; Hands, 2008; Hands \& Larkin, 2006; Schott, Alof, Hultsch, \& Meermann, 2007; Tsiotra, Nevill, Lane, \& Koutedakis, 2009). Physical fitness refers to a set of inherent or achieved personal attributes that relate to the capacity to perform physical activity and/or exercise (Caspersen et al., 1985; Ortega, Ruiz, Castillo, \& Sjøstrøm, 2008). The negative interaction between low motor competence and physical fitness is found to start at an early age (Hands \& Larkin, 2006) and seems to persist into adolescence (Green et al., 2011; Haga, 2009; Hands, Larkin, Straker, \& Perry, 2009; Okely, Booth, \& Patterson, 2001).

Self-perception, is seen as a mediating factor between motor competence, physical fitness and physical activity (Barnett et al., 2008; Cairney, Hay, Wade, Faught, \& Flouris, 2006; Raudsepp \& Liblik, 2002; Raudsepp, Liblik, \& Hannus, 2002), and has been identified as an important psychosocial correlate of motor competence (Piek, Baynam, \& Barrett, 2006; Cantell, Smyth, \& Ahonen, 2003). In the present study, self-perception is defined from a multidimensional perspective and the focus is on the evaluative component of the concept of the self (Harter, 1999). Applied in the theory of competence motivation (Harter, 1987), children's perception of their own competence as positive, may promote physical activity. On the other hand, by avoiding situations where their lack of competence might come into sight, children with low motor competence may miss vital opportunities to develop their physical and social benefits of involvement in physical activity (Piek et al., 2006).

Children with low motor competence are found to have lower self-perception in several sub-domains as well as global-self-worth compared to their peers (Piek et al., 2006;
Poulsen, Ziviani, \& Cuskelly, 2006; Skinner \& Piek, 2001). This seems to persist into adolescence for them in the group with lowest motor competence, while in some of the domains no differences were revealed between the intermediate group and the group with higher motor competence (Cantell et al., 1994; 2003). Thus, indicating that the consequences of low motor competence in children and adolescents are most severe to them with the poorest scores on tests. Additionally, it is found that motor coordination has an indirect impact on emotional functioning, as depression and anxiety, mediated by various self-perception domains (Rigoli, Piek, \& Kane, 2012). Consequently, early competence in motor skills is of considerable significance for children's quality of life development (Mandich, Polatajko, \& Rodger, 2003).

Previous findings indicate that children get a more realistic picture of their own motor competence by age (Rudisill, Mahar, \& Meaney, 1993). Additionally, more recent studies show that even in preschool children there is a modest, but significant relationship between actual motor competence and perceived competence (LeGear et al., 2012; Robinson, 2010). Despite this, young children seem to have positive perceptions of their physical competence although their actual competence is low. This suggests to "provide a window of opportunity for learning and mastering motor skills" (LeGear et al., 2012), thus indicating that knowledge about a child's self-perception may be important in all instructional settings to increase perceived positive competence and motivation for further activity.

Earlier studies have investigated differences in physical fitness (Cantell et al., 2008, Haga, 2008b; 2009; Hands \& Larkin, 2006), physical activity (Barnett et al., 2009; Cantell et al., 2008; Williams et al., 2008; Wrotniak et al., 2006) and self-perception (Piek et al., 2006; Skinner \& Piek, 2000) in children with different levels of motor competence. However, to the best of our knowledge, there has been no research where all these variables have been taken into consideration in the same study. Applied in an educational setting, a thorough investigation of all these variables in 
the same population, may give essential information. Additionally, comparing the children in the lowest motor competence group with the children in the highest group has been questioned as it may make the difference seem larger than it really is (Rivilis et al., 2011). This indicates that one should look at all children from the initial sample and not the extremes of the distribution. Hence, the aim of the present study was to investigate assumed differences in physical fitness, selfperception and physical activity in children at the age of 11 by dichotomizing them into lower motor competence group and higher motor competence group based on their score on Motor Assessment Battery for Children (MABC).

\section{METHOD}

\section{Sample}

Following approval of the experimental protocol by the Norwegian Regional Ethics Committee (ref:2009/958), the total population of the 6th grade school children $(n=82,35$ girls and 47 boys) in a local mainstream primary school in a Norwegian city, were invited to participate in the study. Both parents and children were given verbally and written information about the study. Furthermore, all parents provided written informed consent on behalf of the children involved in the study prior to completing the experimental paradigm, and all procedures were carried out in accordance with the tenets of the Declaration of Helsinki. Approval was obtained for 69 children (29 girls and 40 boys). Two were excluded as they did not meet the inclusion criteria, consisting of no history of learning difficulties or any behavioural, neurological, or orthopaedic problem. Accordingly, 67 children (28 girls and 39 boys) constituted the sample. The mean age of the participants was 11.5 years (SD 0.27 , range 10.91-11.83.

From the sample of 67 pupils, the children were divided into 2 groups on the basis of their MABC scores (see Table 1), and 26 children constitute the lower motor competence (LMC) group. According to the manual of MABC, a score of 13.5 or more is an indicative of a definitive motor problem (Henderson \& Sugden, 1992). In the present study the children scoring at or above a total score of 13.5 (a high score indicates motor problems) were categorized as having lower motor competence (LMC), while the children scoring below 13.5 forms the higher motor competence group (HMC).

Table 1. Total score on the MABC

\begin{tabular}{lcrccccc}
\hline & \multicolumn{3}{c}{ HMC } & \multicolumn{4}{c}{ LMC } \\
& Mean & SD & (n) & & Mean & SD & $(\mathrm{n})$ \\
\hline Girls & 8.13 & 3.45 & 15 & & 19.50 & 4.44 & 13 \\
Boys & 9.12 & 3.14 & 26 & & 18.92 & 3.57 & 13 \\
Whole group & 8.76 & 3.26 & 41 & & 19.21 & 3.96 & 26
\end{tabular}

Note: lower scores equal better performance

$\mathrm{HMC}=$ higher motor competence

$\mathrm{LMC}=$ lower motor competence

\section{Measures}

The Movement Assessment Battery for Children (MABC).

The MABC consists of both quantitative and qualitative components to describe motor competence in children (Henderson \& Sugden, 1992). In the present study the test component of MABC was used. It is a standardised test which provides a quantitative evaluation of children's motor competence, and is divided into four age bands from 4 through 12 years. Age band 4 (for children aged 11-12 years) was used in the present study. Each age band contains eight sub-tests divided into three categories: 1) three tests of manual dexterity, 
2) two tests of ball skills, and 3) three tests of static and dynamic balance. On each sub-test the child receives a score from 0-5, 0 representing the best performance. The scores on each of the eight sub-tests add up a total impairment score. In their manual, Henderson and Sugden (1992, page 109), have made a table with detailed information on the total score distributions and percentiles, which might be useful in research purposes to get more information about detailed differentiations between children.

The MABC has a minimum testretest reliability at any age of 0.75 and an inter-rater reliability of 0.70 (Tan, Parker, \& Larkin, 2001; Henderson \& Sugden, 1992).

Test of Physical Fitness (TPF).

TPF is a test battery that aims to provide a reliable, objective quantification of physical fitness levels in children aged 5-12 years (Fjørtoft, Pedersen, Sigmundsson, \& Vereijken, 2003; 2011). TPF consists of activities that are naturally included in most children's everyday play activities, e.g. jumping, throwing, running and climbing. Additionally, TPF focuses on compound activities that recruit varying combinations of multiple factors such as strength, endurance and motor coordination (Fjørtoft et al., 2003; 2011). The battery consists of nine test items which are the same for all ages (5-12): three items are based on jumping, two on throwing, one on climbing and three on running. Most items also appear in measures such as the EUROFIT (Adam et al. 1998), the AST 6-11 (Bös and Wohlmann, 1987), the FBH-test (Bille, 1992), while the test item 'climbing wall bars' was especially designed for the TPF (Fjørtoft et al., 2003). Test-retest correlation for the total score of the TPF is high, 0.90, and the construct validity of the test was 0.93 for girls and 0.89 for boys (Spearman's rho; Fjørtoft et al. 2003; 2011). The nine test items are explained in Table 2.

Table 2. Test items of physical fitness test (TPF)

\begin{tabular}{|c|c|c|c|}
\hline Domain & Item & Description & Measures \\
\hline \multirow[t]{3}{*}{ Jumping/Balance } & 1 & $\begin{array}{l}\text { Standing broad jump Standing long jump for a } \\
\text { distance }\end{array}$ & Centimetres \\
\hline & 2 & $\begin{array}{l}\text { Jumping a distance of } 7 \mathrm{~m} \text { on two feet as quickly as } \\
\text { possible }\end{array}$ & Time (seconds) \\
\hline & 3 & $\begin{array}{l}\text { Jumping a distance of } 7 \mathrm{~m} \text { on one foot as quickly as } \\
\text { possible on self chosen leg }\end{array}$ & Time (seconds) \\
\hline \multirow[t]{2}{*}{ Throwing } & 4 & $\begin{array}{l}\text { Throwing a tennis ball as far as possible: throw with } \\
\text { self chosen hand, one foot placed in front of the other }\end{array}$ & $\begin{array}{l}\text { Metres and } \\
\text { centimetres }\end{array}$ \\
\hline & 5 & $\begin{array}{l}\text { Putting a medicine ball }(1 \mathrm{~kg}) \text { with both hands as far as } \\
\text { possible: feet parallel and a shoulder width apart and } \\
\text { the ball held against the chest. } \\
\text { Timed climbing and crossing wall bars (height } 255\end{array}$ & $\begin{array}{l}\text { Meters and } \\
\text { centimetres }\end{array}$ \\
\hline Climbing & 6 & $\begin{array}{l}\mathrm{cm} \text {, width } 75 \mathrm{~cm} \text { ); up the first, across two columns to } \\
\text { the right, and down the fourth. }\end{array}$ & \\
\hline \multirow[t]{3}{*}{ Running } & 7 & $\begin{array}{l}\text { Timed shuttle sprint, running back and forth } 5 \mathrm{~m}, 10 \\
\text { times. } \\
\text { Timed running } 20 \mathrm{~m}\end{array}$ & Time (seconds) \\
\hline & 8 & Reduced Cooper test: distance covered in 6 minutes & Time (seconds) \\
\hline & 9 & $\begin{array}{l}\text { running/walking around a marked rectangle }(9 \times 18 \mathrm{~m} \text {, } \\
\text { the size of a } \\
\text { vollevball field })\end{array}$ & Time (seconds) \\
\hline
\end{tabular}

The following materials were used for administering the test items: masking tape, ruler, stopwatch, tennis ball, medicine ball $(1 \mathrm{~kg})$, wall bars at least 4 columns wide, and gymnasium mats. 
The Self Perception Profile for Children (SPPC).

SPPC is a questionnaire devised to tap children's domain-specific judgements of their scholastic competence, social acceptance, athletic competence, physical appearance and behavioural conduct, as well as a separate subscale that assesses global self-worth. Global self-worth is not the sum of the domain-specific subscale scores, but consists of its own set of items assessing the individuals' evaluation of his/her worth as a person (Harter, 1985; 1999). The test consists of a structured-alternative format in, which each SPPC item consists of two opposite descriptions, e.g. "Some children wish they could be a lot better at sports" but "Other children feel they are good enough at sports". Firstly, the individual is asked to decide which of a pair of statements best reflects them, and secondly, they decide if it is "really true" or "sort of true" for them. This structure decreases the tendency to give socially desirable responses (Harter, 1982, 1999).

Each of the sub domains contains six items, constituting a total of 36 items. A mean score is computed for each subscale to form a profile of the child's perceived competence with respect to the different domains. Items are scored either $4,3,2$ or 1 , where a score of
4 reflects the highest perceptions of competence and a score of 1 reflects the lowest perceptions of competence and a mean of 2.5 or more reflects a positive selfperception (Harter, 1985).

SPPC is found to be a reliable and valid self-report measure for assessing children's self-perception (Harter, 1985; Muris, Meesters, \& Fijen, 2003). In the present study the translated Norwegian version was used (Moen, Espnes, Estil, \& Kjelsås, 2003).

\section{Physical activity (PA).}

Two questions about physical activity (Table 3) were used to record the respondent's weekly physical activity level in sports and activity. These questions were modified versions of the physical activity questions in the World Health Organization health behaviour in schoolchildren (WHO HBSC; WHO, 2000). The children were asked to report frequency and total amount of time (duration) spent in vigorously physical activities outside school hours. The questions of vigorous physical activity in WHO HBSC are reported to have acceptable validity and reliability (Booth et al., 2001), and are found to be a good indicator of physical fitness (Rangul et al., 2008).

Table 3. Questions about physical activity outside school

Outside school hours: How many days a week do you exercise so much that you (break into) sweat or get out of breath?

$\square$ Never
$\square$ Once a week
$\square 2-3$ days per week
$\square 4-5$ days per week
$\square 6-7$ days per week

Outside school hours: How many hours per week do you exercise so much that you (break into) sweat or get out of breath?

$\square$ Never
$\square$ Less than 1 hour
$\square 1-2$ hours
$\square 2-5$ hours
$\square$ More than 5 hours

Note Numbers in parentheses indicate score used for each response when recoding each category into measurable categories 


\section{Procedure}

Participants were tested over three sessions, and all the testing took place during the school day at the children's school. First, the questionnaires of SPPC and PA were completed in the classroom, by all children at the same time. The administrator explained carefully how the questionnaires were to be completed, read the statements twice and then gave the children sufficient time to answer each question. During this session, the children were allowed to ask if they thought something was unclear in the questionnaire. Within two weeks, the children were tested on the MABC and the TPF, respectively. The $M A B C$ was executed in classrooms in accordance with the manual of MABC. The TPF was carried out in the school sports hall. Before the child started, every test item was explained and demonstrated. Test items 1-6 on TPF were performed twice each, and the best score was used. The running tests were performed only once. If the child made a procedural error during the test, performance was interrupted and the test item repeated. Individually tested MABC and TPF, and the organizing of the tests, ensured that the children were not able to compare their performance with each other. Assistants that had been trained in the test protocols tested all the children individually. All children completed the tasks.

\section{Data reduction and analysis}

Data analysis was carried out via SPSS version 19.0 for Windows (SPSS Inc., Chicago, IL, USA). In order to express the child's total performance on the TPF as one score, a total test score was calculated by transforming the test item scores into a standardized score (zscores) from the mean of the whole sample (n $=67$ ). Higher scores indicate higher performance on the tasks. In order to express the amount of physical activity, the response alternatives were recoded in numeric categories (see Table 4). Differences between children with higher or lower motor competence in physical fitness, physical activity and self-perception were analyzed by using non-parametric Mann-Whitney U Test. Probability values of $\mathrm{p}<.05$ were used to determine significance.

\section{RESULTS}

The results in Table 4 show highly significant differences on all tasks of TPF between children scoring at or above 13.5 compared to below 13.5 on MABC. This indicates that children categorized with LMC performed poorer on all tasks of physical fitness than the HMC-group. Additionally, the LMC-group had lower self-perception in athletic competence and social acceptance. According to days and hours of hard physical activity, results show a higher self-reported participation in physical activity in children in the HMC-group compared to the LMC-group. In table 1 the total-scores of MABC in the HMC- and LMC-group are described. 
Table 4. Mean (SD) score for TPF, SPPC and PA for the two groups: HMC and LMC:

\begin{tabular}{|c|c|c|c|c|c|}
\hline & \multicolumn{2}{|c|}{$\begin{array}{l}\text { HMC } \\
\text { (higher motor competence) } \\
\mathrm{N}=41\end{array}$} & \multicolumn{2}{|c|}{$\begin{array}{l}\text { LMC } \\
\text { (lower motor competence) } \\
\mathrm{N}=26\end{array}$} & \multirow[b]{2}{*}{ p-value * } \\
\hline & $\begin{array}{c}\mathrm{M} \\
\text { (mean) }\end{array}$ & SD & $\begin{array}{c}\mathrm{M} \\
\text { (mean) }\end{array}$ & SD & \\
\hline \multicolumn{6}{|l|}{ Test of physical fitness: } \\
\hline Standing broad jump (cm) & 148.37 & 20.46 & 124.15 & 16.50 & $.000 *$ \\
\hline Jumping on two feet (s) & 3.20 & .69 & 3.69 & .62 & $.000^{*}$ \\
\hline Jumping on one foot (s) & 2.78 & .52 & 3.30 & .59 & $.000^{*}$ \\
\hline Throwing a tennis ball (m) & 20.18 & 4.91 & 16.26 & 4.58 & $.002 *$ \\
\hline Pushing a medicine ball (m & 5.35 & .75 & 4.66 & .79 & $.001 *$ \\
\hline Climbing wall bars (s) & 7.75 & 1.92 & 10.08 & 3.23 & $.000^{*}$ \\
\hline Shuttle run (s) & 22.50 & 1.34 & 24.54 & 1.95 & $.000^{*}$ \\
\hline Running 20m (s) & 4.13 & 0.19 & 4.46 & .35 & $.000 *$ \\
\hline Reduced Cooper test (m) & 1078.15 & 113.94 & 979.15 & 131.877 & $.005 *$ \\
\hline Total test score (z-score) & 3.11 & 5.60 & -4.9 & 6.74 & $.000 *$ \\
\hline \multicolumn{6}{|c|}{ Self-Perception Profile for Children (SPPC): } \\
\hline Scholastic competence & 3.24 & .61 & 3.05 & .57 & .132 \\
\hline Social acceptance & 3.46 & .40 & 2.79 & .96 & $.003 *$ \\
\hline Athletic competence & 3.14 & .47 & 2.67 & .71 & $.004 *$ \\
\hline Physical appearance & 3.37 & .56 & 2.90 & .98 & .097 \\
\hline Behavioural conduct & 3.19 & .56 & 3.26 & .49 & .734 \\
\hline Global self-worth & 3.44 & .46 & 3.11 & .80 & .121 \\
\hline \multicolumn{6}{|l|}{ Physical activity: } \\
\hline Days $^{a}$ & 3.15 & .76 & 2.65 & .80 & $.017 *$ \\
\hline Hours $^{\mathrm{a}}$ & 3.46 & .68 & 2.73 & .87 & $.001 *$ \\
\hline
\end{tabular}

Note. SD, standard deviation; $M$, mean;

a) Mann-Whitney U-test

${ }^{a}$ Numbers of days and hours of physical activity was recoded into measurable categories when analyzing data. The categories used for each response were: 0, 1, 2, 3, 4, indicating as follows: never, once a week , 2-3, 4-5, 6-7 days a week and never, less than 1 hour, 1-2, 2-5, more than 5 hours a week.

${ }^{b}$ Items of SPPC are scored either 4, 3, 2 or 1, where a score of 4 reflects the highest perceptions of competence and a score of 1 reflects the lowest perceptions of competence. 


\section{DISCUSSION}

The aim of the present study was to investigate assumed differences in physical fitness, selfperception and physical activity in children with lower motor competence (LMC) and higher motor competence (HMC) based on total score on MABC. The results showed that the children in the LMC- group performed significantly poorer in all nine tasks of Test of Physical Fitness (TPF) than the HMC-group. Additionally, children in the LMC-group had lower scores on perception of social acceptance and athletic competence, and reported that they spent less time in physical activity than children in the HMC-group.

The present study revealed significant differences in fitness components in children with LMC compared to children with HMC, which is in line with studies using total score on MABC in separating the groups based on level of motor competence (Cantell et al., 2008; Haga 2008b; Schott et al., 2007). Especially, lower performance of all components of the TPF in the LMC-group, is in line with the findings reported by Haga (2008b; 2009). However, she investigated only the children with the lowest and highest scores of MABC, which could have exaggerated the differences between the groups (Rivilis et al., 2011). By including the whole sample, the findings lend further support to the previous indications of poorer performance on physical fitness components in children with the lowest motor competence. The test items of TPF are compound and consist of several fitness components, such as strength, endurance, motor coordination and speed (Fjørtoft et al., 2003; 2011). Cardio-respiratory capability, muscular fitness, and speed/agility are emphasized as the main fitness components related to health in childhood and adolescence (Ortega et al., 2008), all of which benefit from a physically active lifestyle in early years reducing the risk of disease later in life (Bouchard et al., 2007). Lower scores in all these components in the LMC-group may influence the opportunities for these children to be active.

The results revealed that the LMCgroup, participated less in physical activity (with high intensity) than children in the HMC-group. The results were based on selfreported physical activity including sweating and breathlessness, which according to Kurtze et al. (2008) represent hard or vigorous physical activity. This may indicate that the two groups in the current study differ in days and hours of weekly hard physical activity. This is in line with previous studies investigating differences in physical activity in children with varying motor competence (Barnett et al., 2009; Williams et al., 2008; Wrotniak et al., 2006). Hard or vigorous physical activity seems to yield greater benefits than moderate activity to components of health related physical fitness (Ortega et al., 2011, Hopkins et al., 2009). Hence, the reported lower levels of physical activity of children in the LMC-group could in part explain the differences in scores of TPF between the groups in the present study. As well as less physical activity, lower levels of performance in fitness tests in the LMC-group may be influenced by coordinative challenges to perform the actual task, more taxed and less efficient execution of the movements (Cantell et al., 2008; Hands \& Larkin, 2006).

The present study revealed a significant difference in perceived athletic competence and social acceptance in children in the LMC-group compared to children in the HMC group. Children in the LMC-group perceived themselves as less competent in the athletic domain than their peers. This is a rather consistent result and in line with previous studies using Harter's instruments with subjects from preschool to adolescence (Cantell et al., 1994; 2003; LeGear et al., 2012, Piek et al., 2006: Robinson, 2010; Skinner \& Piek, 2001). Despite less consistency, less perceived social acceptance is also revealed in some studies (Rose, Larkin \& Berger, 1997; Skinner \& Piek, 2001). Cantell et al. (2003) compared the selfperception of children separated in three levels of motor competence: motor problem, intermediate and a control group with normal motor competence. They found that the children with motor problems had the lowest perceptions of athletic and scholastic competence while the differences between the 
intermediate and control groups were less pronounced. The current study revealed lower self-perception in the physical and social domain in the LMC-group. Despite these findings, their self-perception scores did not indicate definite low self-perception in these domains (as their scores are above 2.5). Applied in the perspective of Harters' competence motivation theory, focusing on areas where these children experience mastery may be of importance for further engagement in physical active pursuits. Additionally, one may support LeGear's statement about using positive self-perception as a possibility to promote activity even if the actual competence is low (LeGear et al., 2012). According to the Norwegian physical education curriculum, promotion of positive self-perception and mastery are two of the main purposes, and the pupils' effort is part of the evaluating system (Utdanningsdirektoratet, 2012). There are indications of positive effects of interventions with motor training in school. "Motor development as Ground of Learning" (MUGI) is an example of such an intervention, and it emphasizes success instead of failure, mastery and automation of known skills with increased self-esteem and motivation as a result (Ericsson, 2011). This program is in line with the focus in a mastery-oriented climate (Wadsworth, Robinson, Rudisill \& Gell, 2013). A mastery-oriented climate focus on factors such as learning and development, cooperation, creativity, self-worth, and comparing results to own previous results and is based on intrinsic motivation (Wadsworth et al., 2013).

MABC was especially designed for identification of children with mild to moderate motor difficulties (Henderson \& Sugden, 1992) and never intended to differ between children at or above average profiles (Larkin \& Rose, 2005). This indicates that it does not seem appropriate to separate children in groups of low and high motor competence, but rather use the term "higher motor competence" for the children scoring less than 13.5 on MABC. Despite the fact that MABC should include everyday motor skills (Henderson \& Sugden, 1992), the high scores (lower motor competence) of many of the children (See Table 1) could be a result of lack of experience with the aspects measured in the MABC. Similarly, the test items themselves could have influenced the results in TPF. Although, the test items of TPF are designed to be familiar and well known activities (Fjørtoft et al., 2003) it is possible to argue that some of the tasks are more familiar to the most active children.

The relatively small sample size must be taken into account. By increasing sample size with children from several schools, one will have increased the external validity of the present study. However, the results may be important to promote children's health behavior. Applied in a physical education setting, the current research has several implications. For example, it may be especially important to promote a positive perception of own competence, and emphasize effort and mastery rather than comparison of results in order to increase motivation for activity.

\section{Perspectives}

The present research may extend the fundamental knowledge concerning individual constraints, such as lower levels of physical fitness, self-perception and physical activity in the LMC-group compared to children with HMC. The children in the present study were at the age of 11, indicating that they have not been introduced to grades yet. Based on the main purposes of the curriculum of physical education, there is reason to believe that to introduce a mastery-oriented climate in middle school may promote children's understanding of the importance of effort and fair play. Furthermore, this may contribute to a more favorable view on grades, as something that evaluate one's effort and willingness to practice, as well as the actual physical and motor competence. A mastery-oriented perspective may facilitate better opportunities for well-being and development in physical education for groups of children with different challenges, such as the LMC-group in the current study. This is supported in a previous study of children with motor difficulties, reporting that participants' perception of a 
mastery-oriented climate positively affected their perception of competence in physical education (Dunn, 2000). The present findings highlight the importance of suitable adaption of physical activity in order to optimize individual development.

\section{REFERENCES}

Adam, C., Klissouras, V., Ravazollo, M., Renson, R., \& Tuxworth, W. (1998). Eurofit: European test of physical fitness: Handbook. Council of Europe, Commitee for the Development of Sport, Rome, Italy.

Andersen, L. B., Harro, M., Sardinha, L. B., Froberg, K., Ekelund, U., Brage, S., \& Anderssen, S. A. (2006). Physical activity and clustered cardiovascular risk in children: A cross-sectional study (The European Youth Heart Study). Lancet, 368, 299-304.

Barnett, L. M., Morgan, P. J., van Beurden, E., \& Beard, J. R. (2008). Perceived sports competence mediates the relationship between childhood motor skill proficiency and adolescent physical activity and fitness: a longitudinal assessment.

International Journal of Behavioral Nutrition and Physical Activity, 5, 40.

doi: 1479-5868-5-40 [pii] 10.1186/1479-5868-5-40

Barnett, L. M., van Beurden, E., Morgan, P. J., Brooks, L. O., \& Beard, J. R. (2009). Childhood motor skill proficiency as a predictor of adolescent physical activity. Journal of Adolescent Health, 44 (3), 252259. doi: S1054-139X(08)00295-4 [pii]

10.1016/j.jadohealth.2008.07.004

Bille, B., Brieditis, K., Ekstrøm, B., \& Esscher, E. (1992). Fbh provet, erfarenheter från folke bernatottehemmet. Motorika, Ørebro, Sweden.

Booth, M. L., Okely, A. D., Chey, T., \& Bauman, A. (2001). The reliability and validity of the physical activity questions in the who health behaviour in schoolchildren (HBSC) survey: A population study. British Journal of Sports Medicine, 35, 263-267.

Boreham, C., \& Riddoch, C. (2001). The physical activity, fitness and health of children. / activite physique, condition physique et sante des enfants. Journal of Sports Sciences, 19, 915-929.

Bouchard, C., Blair, S. N., \& Haskell, W. L. (Eds.). (2007). Physical activity and Health. Human Kinetics, Leeds, UK.

Cairney, J., Hay, J. A., Faught, B. E., \& Hawes, R. (2005). Developmental coordination disorder and overweight and obesity in children aged 9-14 y. International Journal of Obesity, 29, 369372.

Cairney, J., Hay, J. A., Wade, T. J., Faught, B. E., \& Flouris, A. (2006). Developmental coordination disorder and aerobic fitness: is it all in their heads or is measurement still the problem? American Journal of Human Biology, 18 (1), 66-70. doi: 10.1002/ajhb. 20470

Cantell, M., Crawford, S. G., \& Tish DoyleBaker, P. K. (2008). Physical fitness and health indices in children, adolescents and adults with high or low motor competence. Human Movement Science, 27 (2), 344362. doi: S0167-9457(08)00013-4 [pii]

10.1016/j.humov.2008.02.007

Cantell, M. H., Smyth, M. M. \& Ahonen, T. P. (1994) Clumsiness in adolescence: educational, motor, and social outcomes of motor delay detected at 5 years. Adapted Physical Activity Quarterly, 11 (2), 115129.

Cantell, M. H., Smyth, M. M., \& Ahonen, T. P. (2003). Two distinct pathways for developmental coordination disorder: persistence and resolution. Human Movement Science, 22 (4-5), 413-431. doi: S0167945703000642 [pii]

Caspersen, C. J., Powell, K. E., \& Christenson, G. M. (1985). Physical activity, exercise, and physical fitness: definitions and distinctions for health-related research. Public Health Reports, 100 (2), 126-131.

Dunn, J.C. (2000). Goal orientations, perceptions of the motivational climate, and perceived competence of children with movement difficulties. Adapted Physical Activity Quarterly, 17, 1-19.

Ericsson, I. (2011). Effects of increased physical activity on motor skills and marks in physical education: an intervention 
study in school years 1 through 9 in Sweden. Physical Education \& Sport Pedagogy, 16 (3), 313-329.

Fjørtoft, I., Pedersen, A. V., Sigmundsson, H., \& Vereijken, B. (2011). Measuring physical fitness in children who are 5 to 12 years old with a test battery that is functional and easy to administer. Physical Therapy, 91 (7), 1087-1095. doi: ptj.20090350 [pii] 10.2522/ptj.20090350

Fjørtoft, I., Pedersen, A. V., Sigmundsson, H., \& Vereijken, B. (2003). Testing Children's Physical Fitness- Developing a New Test for 4-12 Years Old Children. Report (IS1256), The Norwegian Social and Health Ministry, Oslo Norway

Green, D., Lingam, R., Mattocks, C., Riddoch, C., Ness, A., \& Emond, A. (2011). The risk of reduced physical activity in children with probable developmental coordination disorder: A prospective longitudinal study. Research in Developmental Disabilities, 32 (4), 1332-1342. doi: 10.1016/j.ridd.2011.01.040

Haga, M. (2008b). Physical fitness in children with movement difficulties. Physiotherapy, 94 (3), 253-259.

Haga, M. (2008a). The relationship between physical fitness and motor competence in children. Child: Care, Health and Development, 34 (3), 329-334.

Haga, M. (2009). Physical fitness in children with high motor competence is different from that in children with low motor competence. Physical Therapy, 89(10), 1089-1097. doi: ptj.20090052 [pii] 10.2522/ptj.20090052

Hands, B. (2008). Changes in motor skill and fitness measures among children with high and low motor competence: A five-year longitudinal study. Journal of Science and Medicine in Sport, 11 (2), 155-162.

Hands, B., \& Larkin, D. (2006). Physical fitness differences in children with and without motor learning difficulties. European Journal of Special Needs Education, 21 (4), 447-456. doi: 10.1080/08856250600956410

Hands, B., Larkin, D., Parker, H., Straker, L., \& Perry, M. (2009). The relationship among physical activity, motor competence and health-related fitness in 14-year-old adolescents. Scandinavian Journal of Medicine \& Science in Sports, 19(5), 655-663.

Harter, S. (1982). The Perceived Competence Scale for Children. Child Development, 53 (1), 87-97.

Harter. (1985). Manual for the Self-Perception Profile for Children: Revision of the Perceived Competence Scale for Children. Denver, CO: University of Denver.

Harter, S. (1987). The determinants and mediational role of global self-worth in children. In N. Eisenberg (Ed.), Contemporary issues in developmental psychology (pp. 219-242). New York: Wiley.

Harter, S. (1999). The Construction of the Self. New York: The Guilford Press.

Haywood, K.M., \& Getchell, N. (2009). Life span motor developement (5th ed): Campaign, Human Kinetics

Henderson, S. E., \& Sugden, D. A. (1992). Movement Assessment Battery for Children. The Psychological Corporation, Kent,UK.

Hopkins, N. D., Stratton, G., Tinken, T. M., McWhannell, N., Ridgers, N. D., Graves, L. E., . . . Green, D. J. (2009). Relationships between measures of fitness, physical activity, body composition and vascular function in children. Atherosclerosis, 204, 244-249.

Kurtze, N., Rangul, V., Hustvedt, B. E., \& Flanders, W. D. (2008). Reliability and validity of self-reported physical activity in the nord-trondelag health study: Hunt 1. Scandinavian Journal of Public Health, 36 (1), 52-61.

Lalkhen, A.G. \& McCluskey, A. (2008). Clinical tests: sensitivity and specificity. Critical

Care and Pain, 8 (6), 221-223.

Larkin, D. \& Rose, E. (2005). Assessment of Developmental Coordination Disorder. In:

Developmental Coordination Disorder (pp. 135-154). London \& Philadelphia: Wurr Publishers.

LeGear, M., Greyling, L., Sloan, E., Bell, R. I., Williams, B. L., Naylor, P. J., \& Temple, V. A. (2012). A window of opportunity? 
Motor skills and perceptions of competence of children in kindergarten. International Journal of Behavioral Nutrition and Physical Activity, 9, 29. doi: 10.1186/1479-5868-9-29

Mandich, A. D., Polatajko, H. J., \& Rodger, S. (2003). Rites of passage: understanding participation of children with developmental coordination disorder. Hum Mov Sci, 22 (4-5), 583-595. doi: S0167945703000733 [pii]

Moen, V. V., Espnes, G. A., Estil, L. B., \& Kjelsås, E. (2003). Motor Skills and Selfesteem in Children in a Private and a Public School. New Zealand Journal of Disability Studies (10), 96-116.

Muris, P., Meesters, C., \& Fijen, P. (2003). The Self-Perception Profile for Children: further evidence for its factor structure, reliability, and validity. Personality and Individual Differences, 35(8), 1791-1802.

Okely, A. D., Booth, M. L., \& Patterson, J. W. (2001). Relationship of physical activity to fundamental movement skills among adolescents. Medicine \& Science in Sports \& Exercise, 33(11), 1899-1904.

Ortega, F. B., Ruiz, J. R., Castillo, M. J., \& Sjøstrøm, M. (2008). Physical fitness in childhood and adolescence: a powerful marker of health. International Journal of Obesity, 32 (1), 1-11. doi: 0803774 [pii]10.1038/sj.ijo.0803774

Piek, J. P., Baynam, G. B., \& Barrett, N. C. (2006). The relationship between fine and gross motor ability, self-perceptions and self-worth in children and adolescents. Human Movement Science, 25 (1), 65-75.

Poulsen, A. A., Ziviani, J. M., \& Cuskelly, M. (2006). General self-concept and life

satisfaction for boys with differing levels of physical coordination: the role of goal orientations and leisure participation. Human Movement Science, 25 (6), 839860. doi: S0167-9457(06)00047-9 [pii]10.1016/j.humov.2006.05.003

Rangul, V., Holmen, T. L., Kurtze, N., Cuypers, K., \& Midthjell, K. (2008). Reliability and validity of two frequently used self-administered physical activity questionnaires in adolescents. BMC
Medicine Research Methodology, 8, 47. doi: 10.1186/1471-2288-8-47

Raudsepp, L., \& Liblik, R. (2002). Relationship of perceived and actual motor competence in children. Perceptual and Motor Skills, 94 (3 Pt 2), 1059-1070.

Raudsepp, L., Liblik, R., \& Hannus, A. (2002). Children's and adolescents' physical self-perceptions as related to moderate to vigorous physical activity and physical fitness. /. Pediatric Exercise Science, 14 (1), 97-106.

Rigoli, D., Piek, J. P., \& Kane, R. (2012). Motor coordination and psychosocial correlates in a normative adolescent sample. Pediatrics, 129 (4), e892-900. doi: 10.1542/peds.2011-1237

Rivilis, I., Hay, J., Cairney, J., Klentrou, P., Liu, J., \& Faught, B. E. (2011). Physical activity and fitness in children with developmental coordination disorder: A systematic review. Research in Developmental Disabilities, 32, 894-910.

Robinson, L. E. (2010). The relationship between perceived physical competence and fundamental motor skills in preschool children. Child: Care, Health and Development. 37 (4),589-96. doi: 10.1111/j.1365-2214.2010.01187.x

Rose, B., Larkin, D., \& Berger, B. G. (1997). Coordination and gender influences on the perceived competence of children. Adapted Physical Activity Quarterly, 14 (3), 210221.

Rudisill, M. E., Mahar, M. T., \& Meaney, K. S. (1993). The relationship between children's perceived and actual motor competence. Perceptual and Motor Skills, 76 (3 Pt 1), 895-906.

Sallis, J. F., Prochaska, J. J., \& Taylor, W. C. (2000). A review of correlates of physical activity of children and adolescents. Medicine of Science and Sports Exercise, 32 (5), 963-975.

Schott, N., Alof, V., Hultsch, D., \& Meermann, D. (2007). Physical fitness in children with developmental coordination disorder. Research Quarterly for Exercise and Sport, 78 (5), 438-450.

Skinner, R. A., \& Piek, J. P. (2001). Psychosocial implications of poor motor 
coordination in children and adolescents. Human Movement Science, 20 (1-2), 7394.

Tan, S. K., Parker, H. E., \& Larkin, D. (2001). Concurrent validity of motor tests used to identify children with motor impairment. Adapted Physical Activity Quarterly, 18, 168-182.

Tsiotra, G. D., Nevill, A. M., Lane, A. M., \& Koutedakis, Y. (2009). Physical Fitness and Developmental Coordination Disorder in Greek Children. Pediatric Exercise Science, 21 (2), 186-195.

[Utdanningsdirektoratet] The Norwegian Directorate for Education and Training (2012). [Læreplan i kroppsøving] Physical education cuuriculum. http://www.udir.no/k106/KRO1-03/

Vedul-Kjelsås, V., Sigmundsson, H., Stensdotter, A. K., \& Haga, M. (2012). The relationship between motor competence, physical fitness and self-perception in children. Child: Care, Health and Development, 38 (3), 394-402. doi: 10.1111/j.1365-2214.2011.01275.x

Wadsworth, D. D., Robinson, L. E., Rudisill, M. E., \& Gell, N. (2013). The effect of physical education climates on elementary students' physical activity behaviors. The Journal of School Health, 83, 306-313.

WHO, World Health Organization. (2000). Health and health behavior among young people. Copenhagen: WHO Regional Publications

Williams, H. G., Pfeiffer, K. A., O'Neill, J. R., Dowda, M., McIver, K. L., Brown, W. H., \& Pate, R. R. (2008). Motor Skill Performance and Physical Activity in Preschool Children. Obesity, 16 (6), 14211426.

Wrotniak, B. H., Epstein, L. H., Dorn, J. M., Jones, K. E., \& Kondilis, V. A. (2006). The relationship between motor proficiency and physical activity in children. Pediatrics, 118 (6), e1758-1765. doi: 118/6/e1758 [pii]10.1542/peds.2006-0742 